\title{
Enhanced Learning by Extending Metadata of Learning Objects with Knowledge Objects
}

\author{
Sai Sabitha ${ }^{1}$, Deepti Mehrotra ${ }^{2}$ and Abhay Bansal $^{3}$ \\ $K E C^{1}, A_{S C S}^{2}$, Amity University, India \\ ${ }^{1}$ saisabitha@gmail.com; ${ }^{2}$ mehdeepti@gmail.com; abhaybansal@hotmail.com ${ }^{3}$
}

\begin{abstract}
Students are given a set of prescribed learning objects within a domain area in a technology supported learning environment. Learning to be effective, the content should address the needs of students with various learning styles, promote adoption of a deep approach to learning, and help students to reach a higher level of intellectual gain. The current learning environment provides an opportunity for standardization of learning objects which can be reused, recombined and adapted through the use of LOs. The quality of the learning content delivered to a user also plays an important role and determination of such quality Learning Objects (LO) involves complex processes. An added knowledge to the existing $L O$ can surely benefit the user in many ways and can improve the quality of an object. Metadata plays a bigger role in the delivery of Learning Objects based on user queries and many metadata standards exist which helps in retrieval of these LOs. A method is proposed to tag a new extended metadata called Knowledge Object (KO) of Knowledge Management System (KMS) with LOs. The LOs and KOs can automatically be classified using data mining approaches. K-nearest neighbour approach is used to find the closest KOs to a particular LOs These KOs are considered as extended metadata to fetch a Knowledge Enabled Learning Object as a specialized Knowledge Content to users; thereby the quality of an object in a learning environment is improved.
\end{abstract}

Keywords: Learning Objects; Knowledge Objects; Metadata; Data Mining, KNN

\section{Introduction}

A LO can be of any format such as text, image, graphics, audio or video. Learning Object Repositories (LOR) helps in storing, searching, retrieving, and delivering of LOs. The LOs are fetched and delivered to the user by a data model, Learning Object Metadata (LOM). The actors involved in the life cycle of LOs are an author, publisher, repository maker, policy maker, teachers and students. Authors or teachers are the main content developers. The characteristic features of LOs are reusability, interoperability and manageability.

The learning of students can be a surface approach to learn simple facts, a deeper approach where their focus is to understand the concept and the third is a strategic approach. This detail and extent of the content provided to students may vary depending upon the students' needs. Learners have access to all of the unit content, including the assignment and other relevant resources. Students who take a deep approach to reading try to integrate summaries of material they had read, thereby interpreting the information rather than simply repeating it. In order to achieve higher-order thinking through electronic learning environments, users should correlate new information with old so that meaningful knowledge is acquired [1].

Many research works are being done and models are also proposed for improving the quality of LOs [4]. A learning content can be converged with the implicit knowledge of an 
expert (KO) from KMS to its corresponding LO. Thus the content delivered is dynamic; knowledge enriched and can help learners, especially the advance learners or deep learners. The main factors that engage a learner is by providing quality and relevant content, understanding of it and the ability to interpret it.

Our focus is to add a new metadata (KO) as an extended metadata to one or more LOs, thereby not only delivering relevant content (LOs) indented for a particular topic or lesson but these KOs added, can also help the learners with an enriched learning experience. The need and approach of aggregation of the LO and KO are also proposed many researchers $[18,12$, 14].

\section{Literature Survey}

\subsection{Learning Objects}

LO according to experts is "a reusable, media-independent chunk of information used as a modular building block for e-learning content". It is "any entity, digital or non-digital, which can be used, re-used or referenced during technology supported learning" [7, 2, 17]. These objects have metadata which refers to description that facilitates \& administrates these objects $[16,13]$.

The various metadata standards are Dublin Core Metadata [3], IEEE Learning Object Metadata [7], IMS Global Learning Consortium [8], and Advance Distributed Learning Initiative (ADLI). The IEEE metadata standard is widely used and it aims to develop accredited technical standards, and guides learning technology. It is grouped under categories like general, life cycle, meta-metadata, educational, technical, rights, relation, annotation, and classification categories. The other providers like IMS content packaging model defines a set of structures used to exchange the learning content.

\subsection{Knowledge Object}

Many concepts of KO have been proposed Merrill, [9] \& Ruffner [11]. The tacit knowledge in a knowledge conversion process can be considered as the content of KO. According to Merrill [9] a KO is defined as a record of information that serves as a building block for any KMS. The components of KO are: information component, parts component, property component, activity component and process component. According to Horton [6]," A KO is a chunk of electronic content that can be accessed individually and it completely accomplishes a single goal".

\subsection{Metadata Creation}

Metadata can be generated manually (creators and author), automatically (automated tools) or by semi automatic methods. Metadata harvesting and metadata extraction have been identified as two methods of automatic metadata generation. Metadata harvesting is the process of automatically collecting resource metadata already embedded in or associated with a resource. Metadata extraction is the process of automatically pulling metadata from the resource's content. DC-Dot is one such tool. 


\section{Automatic Meta Data Creation}

\section{Semi Automated Meta Data Creation}

\section{Manual MetaData Creation}

Figure 1. Types of Metadata Creation

\subsection{Learning Object Repositories (LOR)}

LORs help users to search for learning material and they provide simple and advanced searches. Simple search results are given based on input keywords. The advanced search allows users to specify values for specific metadata elements and filters the learning material according to the need of the user. Federated search provides the facility of searching learning materials from other repositories. The well known LORs are MERLOT, EDNA, CGIAR, CAREO, HEAL [10]. Most of these LOR follow IEEE-LOM metadata standard and metadata annotation is done manually.

\subsection{Various Metadata Providers}

Dublin Core metadata contains 15 metadata elements and qualifiers which are useful for general purpose applications. The IEEE Learning Object Metadata describes characteristics of the LOs and classifies into many groups like general, technical etc. The IMS Global Learning Consortium develops and promotes the adoption of open technical specifications for interoperable learning technology. The Can Core Learning Resource Metadata Initiative enhances the ability of educators, researchers and students around the world to search and locate materials from online collections of educational resources. Some of metadata standards and the added extended metadata are shown in "Figure 2".

\begin{tabular}{|c|c|c|c|c|c|}
\hline \begin{tabular}{|l} 
IFEE LOM \\
Ceneral
\end{tabular} & Cancore & \multicolumn{2}{|c|}{$\begin{array}{l}\text { LoM Dublin Core } \\
\text { Metadata }\end{array}$} & \multicolumn{2}{|c|}{ KO as Exte nded Metadata } \\
\hline $\begin{array}{l}\text { 1. Ceneral } \\
2 \text {. Life Cycle } \\
3 \text { Meta- } \\
\text { Metadata } \\
4 \text { Technical } \\
5 . \\
\text { Educational } \\
6 \text {. Rights } \\
7 \text {. Relation } \\
8 \text { Annotation } \\
9 . \\
\text { Classification }\end{array}$ & $\begin{array}{l}\text { 1. Ceneral } \\
\text { 2. Life Cycle } \\
\text { 3. Meta- } \\
\text { Metadata } \\
\text { 4. Technical } \\
\text { 5. Educational } \\
\text { 6. Rights } \\
\text { 7. Relation } \\
\text { 8. Annotation } \\
\text { 9. } \\
\text { Classification }\end{array}$ & $\begin{array}{l}\text { 1. Contributor } \\
2 \text { Coverage } \\
3 \text { Creator } \\
4 . \text { Date } \\
5 \text { Description } \\
6 . \text { Format } \\
7 . \text { Identifier }\end{array}$ & $\begin{array}{l}8 . \\
\text { Langu age } \\
9 . \\
\text { Publisher } \\
10 . \\
\text { Relation } \\
11 \text { Rights } \\
12 \text { Source } \\
13 \text { Subject } \\
14 \text { Tit le } \\
15 \text { type }\end{array}$ & $\begin{array}{l}\text { 1. General } \\
\text { 2. Life Cycle } \\
\text { 3. Meta- } \\
\text { Metadat a } \\
\text { 4. Technical } \\
\text { 5. } \\
\text { Educational } \\
\text { 6. Rights } \\
\text { 7. Relation } \\
\text { 8. Annotation }\end{array}$ & $\begin{array}{l}\text { 9. Classific ation } \\
10 . \mathrm{Know} \text { ledgeObject } \\
10.1 \text { id } \\
10.2 \text { Creator } \\
10.3 \text { Date } \\
10.4 \text { Topic } \\
10.5 \text { Subtopic } \\
10.6 \text { Language } \\
10.7 \text { Sum marise dKO }\end{array}$ \\
\hline
\end{tabular}

Figure 2. Metadata and KO as Extended Metadata

\subsection{Data Mining}

The aim of the data mining process is to extract implicit knowledge from large volumes of data sets and transform it into an understandable structure for further use. It contains several algorithms and techniques for finding novel patterns from large data sets. These are mainly classified into two categories namely, supervised learning (classification) and unsupervised learning (clustering). KNN is a non parametric lazy learner or a classifier. It does not make 
any underlying assumption on the data distribution. It is a technique which uses k-instances as represented points in a Euclidean space $[15,5]$.

\section{Need for Extended Metadata}

- The primary purpose of using a metadata is its ability to describe a resource and allows the user to fetch it. Fundamentally, metadata is an enabler. Metadata attributes are abstracts, keywords, subject, file formats authors, producers, copyright and usage restrictions etc.. Some metadata elements often used by indexes are not included in searchers queries. In current search interfaces, searchers are not being able to find LO, because of the gap between searchers and indexers. However visualization and recommender tools may help to find a relevant LO. Classified $\mathrm{KO}$ added as an extended metadata does help to fetch LOs and improve the content of LO by adding a relevant $\mathrm{KO}$ along with it.

- Metadata is descriptive information about resources like text, image which enhances findability and the sharing of the objects. Many unstructured and unsystematic ways of classification used in information retrieval are to an extent is reducing the retrieval capability. Here the $\mathrm{KO}$ is structured and can be considered as an attribute in existing metadata. But it can add more essence to the learning assets to various end users. The LOM uses a hierarchical structure to organize the relationships between metadata elements and Dublin core uses a flat structure.

- Analysis, synthesis, and evaluation are skills of the highest order in Bloom's taxonomy and they are important in critical thinking. These Objects help in higher order thinking skills and deeper learning and multiple perspectives on the content are made available to the user.

- A learning approach, in a student depends on a particular situation which may involve complex factors. Some students possess the prerequisite knowledge, skills and motivation to learn the subject. Some students depend on an instructional environment. Here,we can add the knowledge object in the instructional environment as a factor to motivate deep approach towards learning.

- A Constructive learning approach has an instructional design that adheres to the principle of constructivism, that knowledge is constructed by the learner, as opposed to being simply transmitted by a teacher and absorbed. This extended metadata helps in such an approach.

- It enhances the current learning object metadata standards to address the learning context and pedagogical instructional role in metadata elements.

- The objects can also be reusable under various context 


\section{Schematic Model}

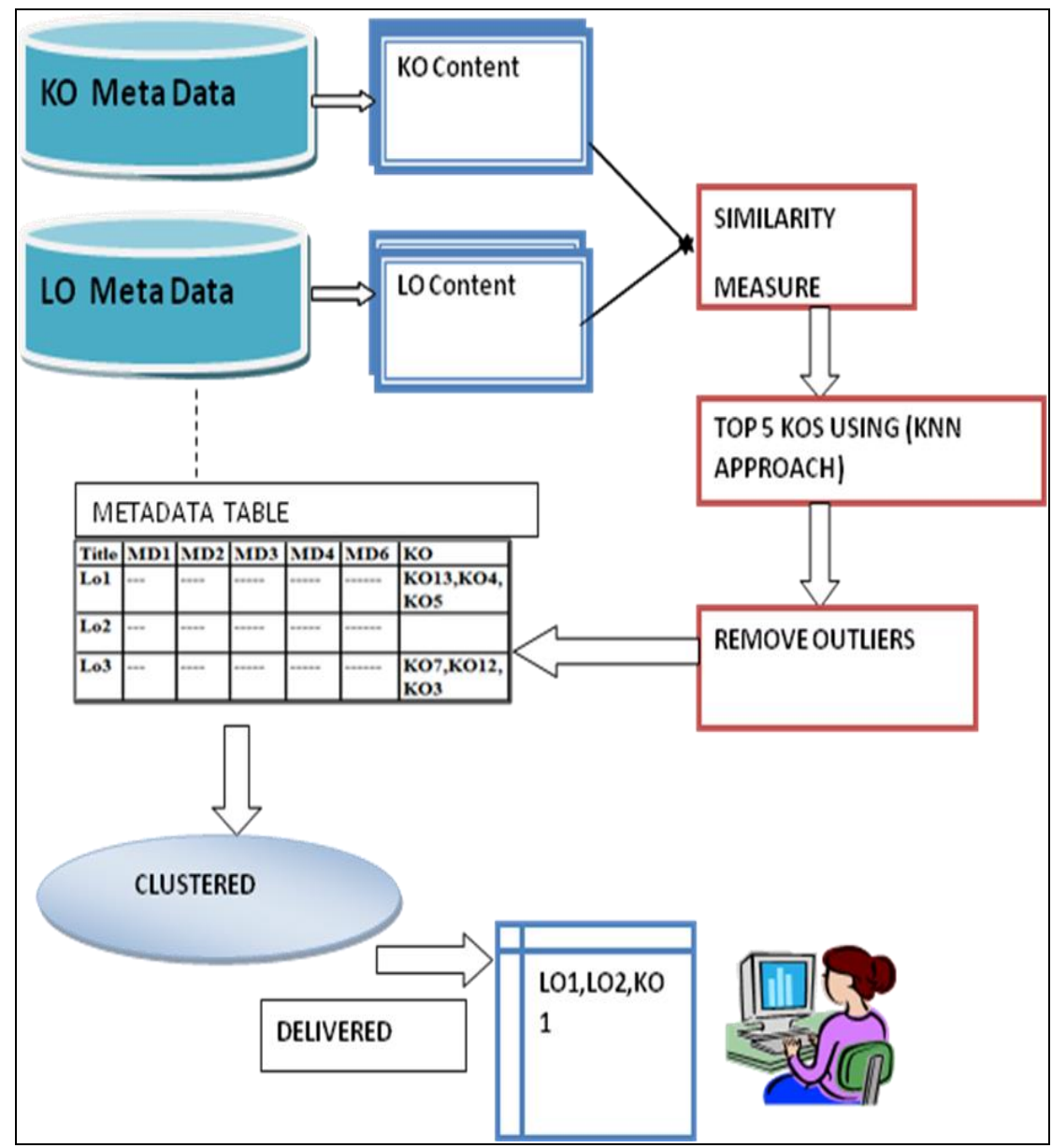

Figure 3. Schematic Model

Steps of the above Model (Figure 3).

1. Generation of LMS and LO.

2. Generation of KMS and KO.

3. Extraction of a LO from LMS and KO from KMS for a particular "topic" in a domain.

4. The proximity measures of these objects using the cosine similarity measure are calculated.

5. Based on the these measures, (Fig.5) Convergence of LO and $\mathrm{KO}$ through data mining "KNN classification" method is done.

6. Classified KO with LO can be called Extended Learning Object (ELO).

7. Now, for each LO we may have one or more associated ELOs which can be further considered as a part of an instructional unit.

8. These classified ELO are added in LO metadata as an extended metadata in the metadata repository.

9. Based on user query, and clustering technique a reduced and relevant LO and a set of KOs called ELO can be delivered to a user. 


\section{Implementation and Results}

Step 1: A set of 30 LOs \& 45 KOs is considered for the domain "data mining". Few records of the classified objects are shown in "Figure 4".

\begin{tabular}{|c|c|c|c|c|c|}
\hline divert & $|t a j| c$ & siltopic & Mategony & allopor ame & content \\
\hline WOI & DAIACEALIN & BNNE & CONCDI & WEENO & 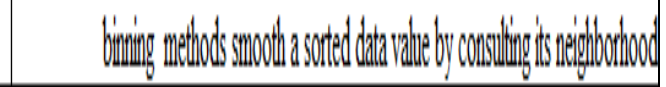 \\
\hline 1010 & OUIER & OOILERAD & 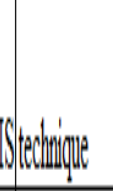 & C & 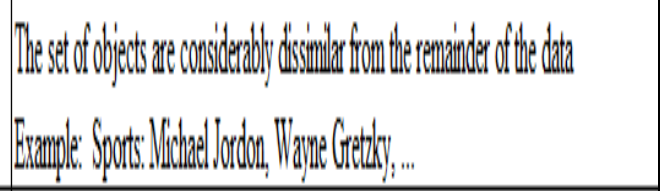 \\
\hline VOI! & ASOCOATOON & PPPEE & tevminiple & $\mathbb{E}$ & 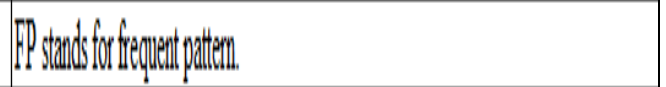 \\
\hline VO1! & CIISTERLIG & DBSCAII & concent & IF & 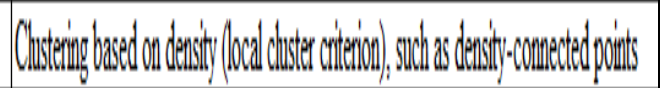 \\
\hline [NO1] & PREDCTION & LAEAREG & tethiniple & $\mathbb{C}$ & 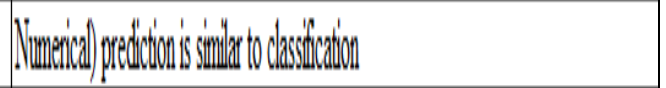 \\
\hline
\end{tabular}

Figure 4. Dataset for a Topic: "Data Mining"

Step 2: The similarity between content of objects in "Figure 4" is generated using cosine similarity measures and are shown in "Figure 5".

\begin{tabular}{|cc|c|}
\hline Object1 & Object2 & Similarity \\
Neasure
\end{tabular}

Figure 5. Similarity Measures

Step 3: K-nearest neighbour approach is used. Based on the granularity of LOs the number of closest KO can be chosen. Here the ' $\mathrm{k}$ ' value is considered as 5 . The first 5 nearest neighbours (KO) with LO and vice-versa is shown in "Figure 6" $\&$ in "Figure 7" respectively. 
First 5 Knowledge Objects to Learning Objects(ids)

First 5 Knowledge Objects to Learning Objects(distance measures

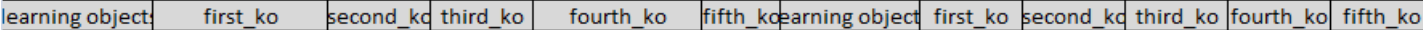

\begin{tabular}{|c|c|c|c|c|c|c|c|c|c|c|c|}
\hline lo1 & 36 & 72 & 63 & 64 & 39 & lo1 & 0.151704 & 0.099662 & 0.068197 & 0.067511 & 0.065169 \\
\hline 102 & 36 & 59 & 40 & 58 & 71 & 102 & 0.148838 & 0.052756 & 0.049894 & 0.033763 & 0.033763 \\
\hline lo3 & 56 & 66 & 58 & 71 & 62 & lo3 & 0.066084 & 0.05869 & 0.047596 & 0.047596 & 0.041129 \\
\hline 104 & 65 & 41 & 68 & 36 & 57 & 104 & 0.333668 & 0.156482 & 0.091279 & 0.083828 & 0.069984 \\
\hline 105 & 38 & 62 & 49 & 58 & 71 & 105 & 0.117551 & 0.115837 & 0.081938 & 0.074616 & 0.074616 \\
\hline 106 & 62 & 38 & 49 & 60 & 40 & 106 & 0.373043 & 0.223426 & 0.198572 & 0.051569 & 0.048754 \\
\hline 107 & 44 & 50 & 36 & 51 & 40 & 107 & 0.274847 & 0.203628 & 0.186221 & 0.035988 & 0.033911 \\
\hline 108 & 40 & 64 & 63 & 39 & 52 & 108 & 0.199309 & 0.1788 & 0.080652 & 0.055584 & 0.046062 \\
\hline 109 & 65 & 41 & 68 & 36 & 57 & 109 & 0.333668 & 0.156482 & 0.091279 & 0.083828 & 0.069984 \\
\hline 1010 & 53 & 66 & 58 & 71 & 52 & lo10 & 0.147256 & 0.145299 & 0.143286 & 0.143286 & 0.134094 \\
\hline Io11 & 63 & 68 & 39 & 43 & 49 & lo11 & \begin{tabular}{|l|l|}
0.17761 \\
\end{tabular} & 0.12678 & 0.120103 & 0.107661 & 0.101836 \\
\hline 1012 & 73 & 75 & 68 & 72 & 32 & 1012 & 0.203334 & 0.203334 & 0.137884 & 0.128906 & 0.110571 \\
\hline Io13 & 73 & 75 & 63 & 39 & 47 & 1013 & \begin{tabular}{|l|l|}
0.13464 \\
\end{tabular} & 0.13464 & 0.127011 & 0.083291 & 0.066617 \\
\hline lo14 & 43 & 57 & 68 & 42 & 58 & lo14 & 0.090517 & 0.084652 & 0.063203 & 0.058012 & 0.054911 \\
\hline Io15 & 36 & 58 & 71 & 65 & 52 & 1015 & 0.317685 & 0.039969 & 0.039969 & 0.039598 & 0.025949 \\
\hline Io16 & 42 & 58 & 71 & 52 & 66 & 1016 & 0.107062 & 0.097425 & 0.097425 & 0.096765 & 0.079604 \\
\hline lo17 & 63 & 39 & 66 & 52 & 58 & lo17 & 0.118686 & 0.082306 & 0.079443 & 0.078911 & 0.077785 \\
\hline lo18 & 68 & 73 & 75 & 63 & 44 & lo18 & 0.196099 & 0.169638 & 0.169638 & 0.087672 & 0.087583 \\
\hline 1019 & 58 & 71 & 68 & 72 & 63 & 1019 & 0.097707 & 0.097707 & 0.080971 & 0.077217 & 0.071931 \\
\hline 1020 & 63 & 39 & 58 & 71 & 59 & lo20 & 0.102392 & 0.075099 & 0.074397 & \begin{tabular}{|l}
0.074397 \\
\end{tabular} & 0.064719 \\
\hline 1021 & 40 & 62 & 52 & 63 & 57 & lo21 & 0.082321 & 0.048955 & 0.040477 & 0.039857 & 0.035443 \\
\hline 1022 & 46 & 70 & 58 & 71 & 63 & 1022 & 0.119449 & 0.110039 & 0.106438 & 0.106438 & 0.095443 \\
\hline 1023 & 65 & 64 & 58 & 71 & 40 & lo23 & 0.058951 & 0.058278 & 0.05737 & 0.05737 & 0.053585 \\
\hline lo24 & 73 & 75 & 66 & 63 & 74 & lo24 & 0.122526 & 0.122526 & 0.085337 & 0.082163 & 0.07226 \\
\hline 1025 & 47 & 42 & 65 & 57 & 61 & 1025 & 0.054733 & 0.052589 & 0.045838 & 0.0451 & 0.042009 \\
\hline 1026 & 47 & 70 & 46 & 61 & 63 & 1026 & 0.104246 & 0.09479 & 0.061623 & 0.049112 & 0.045077 \\
\hline 1027 & 62 & 38 & 49 & 46 & 57 & 1027 & 0.26555 & 0.179068 & 0.155887 & 0.11226 & 0.111182 \\
\hline 1028 & 50 & 58 & 71 & 55 & 56 & 1028 & 0.155408 & 0.053016 & 0.053016 & 0.052755 & 0.04853 \\
\hline 1029 & 64 & 70 & 44 & 46 & 51 & 1029 & 0.168305 & 0.020879 & 0.018497 & 0.017536 & 0.017418 \\
\hline 1030 & 41 & 49 & 32 & 66 & 35 & 1030 & 0.186233 & 0.149819 & 0.145975 & 0.110842 & \begin{tabular}{|l|l|l|}
0.1173 \\
\end{tabular} \\
\hline
\end{tabular}

Figure 6. First 5 Nearest Neighbours of LOs

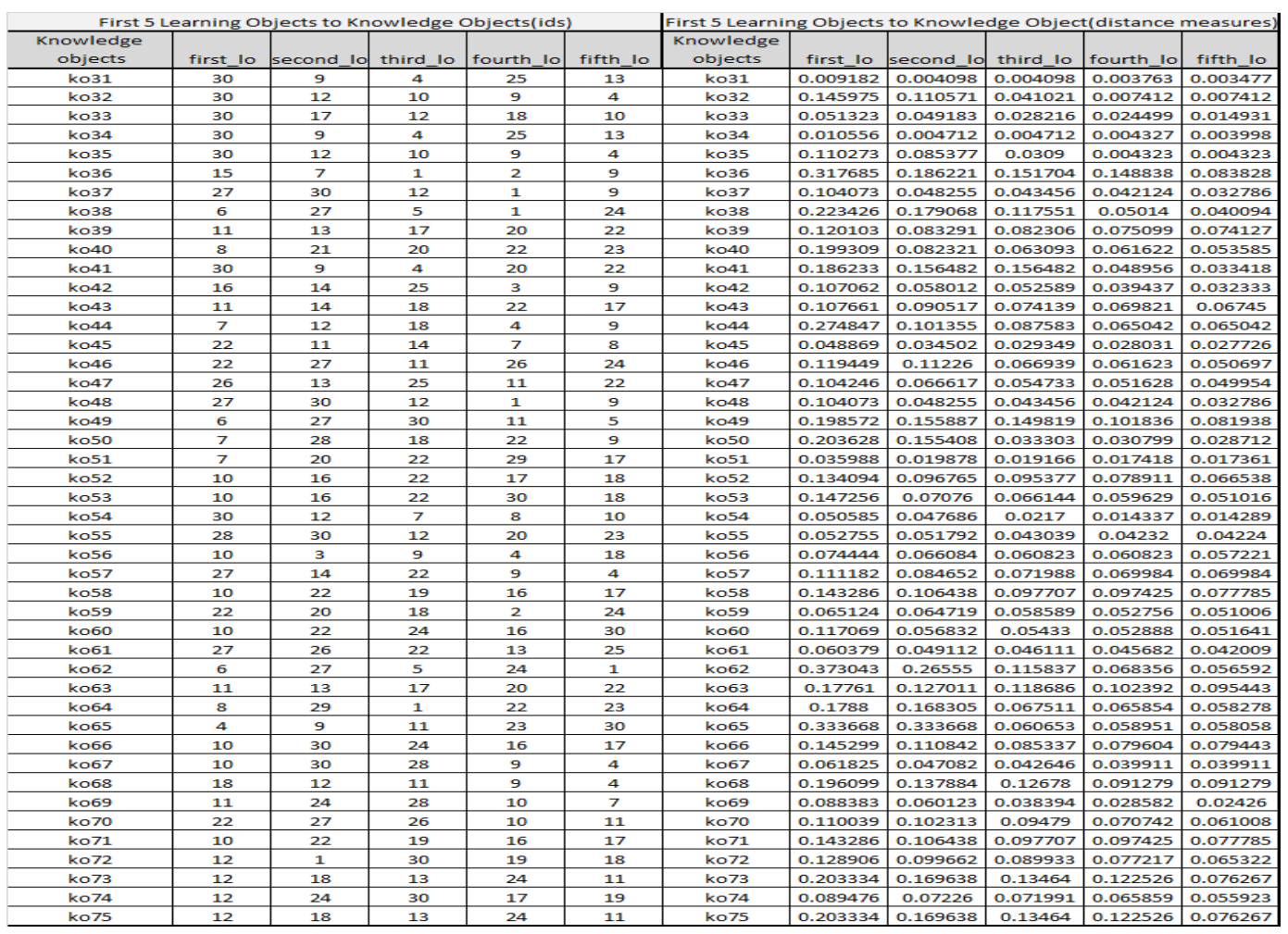

Figure 7. First 5 Nearest Neighbours of KOs 
Step 4: To find out relevant KO, a distance based outlier approach is used. The average distance between first five objects are calculated. Outliers whose average are less than 0.05 are removed. "Figure 8" shows the sorted list of outliers (KO) and their distances with respect to LO. A function in python language was coded to remove the outliers and the output of nearest KOs to LO is shown in "Figure 9".

\begin{tabular}{|c|c|c|c|c|c|c|}
\hline 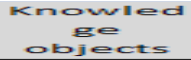 & firste & second & thing & fourtits & Fiftit & \\
\hline 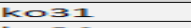 & D.0091182 & 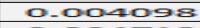 & O-Domaras & D.010 3763 & D. & 0.004924 \\
\hline$k 0034$ & 0.0110556 & $0-0001>112$ & $0.00=112$ & 0.0001325 & 0.003998 & 0.0005661 \\
\hline $\operatorname{kecs} 51$ & $0-035908$ & Di-nill 985 & D.DIII 916 & D-aIl $>21123$ & a-nIl $>351$ & $0.0 \geq 11962$ \\
\hline Lecos 5 & a-m5nses & 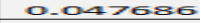 & $m-m>115$ & a-n11-1335 & a-a1l-12309 & an>as> \\
\hline $\operatorname{ken} 3: 3$ & 0.051323 & $0-049113: 3$ & 0.0282116 & $0-0 \geq-1799$ & 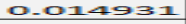 & $07-0: 363$ \\
\hline $1600-45$ & a-OMEBES & $a-0=-1502$ & $a-a \geq 9=-9$ & $a-a \geq 0 a \geq 1$ & $a-a \geq->26$ & 口. \\
\hline keone-7 & 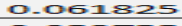 & a.an-7anz & $0.0426-6$ & ロ・-ロ399111 & 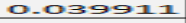 & an-an-5:-5 \\
\hline $\operatorname{kocs}$ & 0.052755 & 0.051532 & $a-a-303=3$ & ㅁ.-01232 & a.-anz2-14 & $0.07-15-23$ \\
\hline $\operatorname{kec} 35$ & 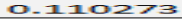 & D.0083 & $0-0305$ & $0-004323$ & $0-0004323$ & $0-07503$ \\
\hline kcons & $0-0 \cos 383$ & 0.06001123 & $0.03839-1$ & 0.028582 & $0-02426$ & D. - \\
\hline $\operatorname{kec} \bar{E} 1$ & 9.060:35 & 0.049112 & 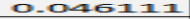 & $0-015652$ & $0-012009$ & $0-0-12559$ \\
\hline $\operatorname{kcos} 3$ & $0-110-10>3$ & 0.018255 & $0.013<56$ & 0.0121121 & 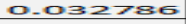 & $0.05-1139$ \\
\hline $\mathrm{kcos}=1 \mathrm{~B}$ & $0-10-10>3$ & $0-0-12255$ & $0-073256$ & $0-a>212 \geq 1$ & $0-032-36$ & $0-05-1139$ \\
\hline $\operatorname{kcos}-12$ & a- 1 Lajáz & a.0.3allz & 0.052589 & $0-039437$ & $0-032333$ & 0.055386 \\
\hline $\operatorname{kec} 59$ & $0-06512-1$ & $0-106-1>119$ & $0-05=585$ & $0-052>56$ & a-as 100 a & $0-05=139$ \\
\hline $\mathrm{k} 0 \mathrm{~B} 2$ & $0-11-4595$ & 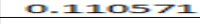 & $0.0 \geq 10 \geq 1$ & $0.00=112$ & a $-\arg -112$ & $0.0062-3$ \\
\hline $\mathrm{kan} 5 \mathrm{~s}$ & $0-0>-1>-1$ & D.MEGDE-4 & $0-1060023$ & 0.060823 & $0-05=221$ & D.DE:3:53 \\
\hline $\operatorname{ken}-17$ & $a-10-1>-16$ & 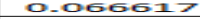 & $0-05-1=33$ & 0.051625 & $0.04995-1$ & $0-065436$ \\
\hline LEER & 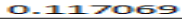 & D.M5ER:32 & 0.05433 & D.05 $028=$ & $005116-1$ & D.MEES5-2 \\
\hline$k=0=-1$ & D. - Desen-5 & $0-3226$ & $0^{\prime}-a_{1}=9$ & 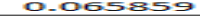 & $0-055923$ & $a-a>11+a \geq$ \\
\hline $\cos 5=$ & $0-11-17256$ & $0-1090-6$ & $0-0 \cos 14-4$ & $0-059629$ & $0-a 510116$ & $0-0>0961$ \\
\hline $\operatorname{kec}=5$ & 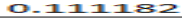 & $0-0 \times-4652$ & $0.0>11900$ & 0.069902 & $0.06930-1$ & 0 - \\
\hline $\operatorname{ksc}-3$ & O - 1105601 & 0.0000115 & $a_{-\infty}-113=$ & $0-0.95=1$ & 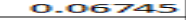 & O.-OD:119115 \\
\hline $\operatorname{ken}=0$ & $0-11194-9$ & 메료 & 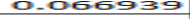 & 0 -0口11023 & on-onomas & $0+0=21194$ \\
\hline $\operatorname{kec} 33$ & 묘 - I & 0.003231 & $0-0=230$ & ㅁ-1-0 & 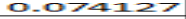 & $9=5$ \\
\hline $\mathrm{kec}=0$ & 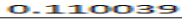 & $0-1023113$ & ㅁ-109479 & $0.0-10=42$ & $0-0611000$ & 0.0. \\
\hline$k 050$ & $10-203623$ & $0-155400$ & $\square-\square=3303$ & $0-030>95$ & $0-0 \geq 3-12$ & a-agas \\
\hline$k e,-10$ & a-1199309 & $0-0=2321$ & O-DE:30193 & 0.0611622 & 0.053525 & O. - \\
\hline $\operatorname{kec} 52$ & $0-128906$ & $0-099652$ & ㅁ. & 0.052115 & $0-065322$ & 0.002200 \\
\hline$k \operatorname{sen} 2$ & a - $13=4001$ & 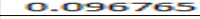 & $0-0053=5$ & ロ-ロラ3911 & ODEGS 32 & $0-00-13=7$ \\
\hline kones & $0-1142 \geq 93$ & a - Illab-12 & $0-0=5337$ & 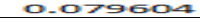 & $0-0>9>-13$ & a - Ilanilas \\
\hline $\operatorname{kcos} 3$ & $0-1-13286$ & O - $1006=3$ & a.dos $>$ - & $0-05-125$ & a.ar->35 & ㅁ - $110-152=$ \\
\hline $\mathrm{kac}-1$ & $0-1123286$ & $0-106 \pi 3=$ & a.dos $>$ - & $0-095>25$ & $0.05-385$ & 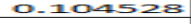 \\
\hline $\mathrm{kcos}=\mathrm{E}$ & O-1 - Tes: & D-11683as & a-anjsit & 0.065:5-1 & a-0 & ation \\
\hline $\operatorname{Lec}=-11$ & a-1 $1253=3$ & a-1 senas? & $a_{-1}-15-123$ & O-MUES56 & $a-n=3-11=$ & $0-116311-1$ \\
\hline$k=0, \pi$ & $0.2-4=2-$ & $0-1001355$ & $a-0:-5=3$ & a.0.65an? & 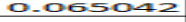 & 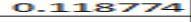 \\
\hline $\mathrm{kec}=\mathrm{B}$ & $0.223-26$ & a - Il 7006 & a - $111-551$ & $0-05011$ & 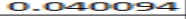 & $0-1122056$ \\
\hline $\operatorname{kec} \sigma 3$ & $a-11561$ & $a-1 \geq-a 111$ & 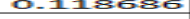 & $0-102392$ & $0-\infty 95-2=$ & $a-1 \geq-2 \geq 2$ \\
\hline KEDEE & a. - 1lsanss & 메 - 135884 & $a_{-1}-a=8$ & $0.0012=3$ & $0-\cos 11 \geq 7=$ & - $112=$ \\
\hline $\operatorname{kec} 0=3$ & alloss 12 & 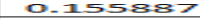 & 口. 11498119 & 口-110 & G. & - IIB \\
\hline $\mathrm{kec} 53$ & 0.203334 & $0-169638$ & ㅁ. $11346-1$ & $0-1122526$ & $0-0>6265$ & 0 - $11 \geq 2=1$ \\
\hline $\mathrm{kec}=5$ & $0.20333-4$ & $0-169632$ & 미 - I $3246-1$ & $0-122526$ & $00-106265$ & $0_{-1}-11281$ \\
\hline $\mathrm{keO}$ & $0-333665$ & 0.333658 & O-DEDES & a-as:351 & a-assass & a. 165 \\
\hline $5 \geq 2$ & $0-3>30-3$ & .555 & D- 11.58 & 062356 & 2 & 58 \\
\hline 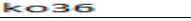 & a. 31 - & a - I & $a-15=11-a=1$ & $483: 3$ & ㅁo & 7655 \\
\hline
\end{tabular}

Figure 8. Distance Based Outliers

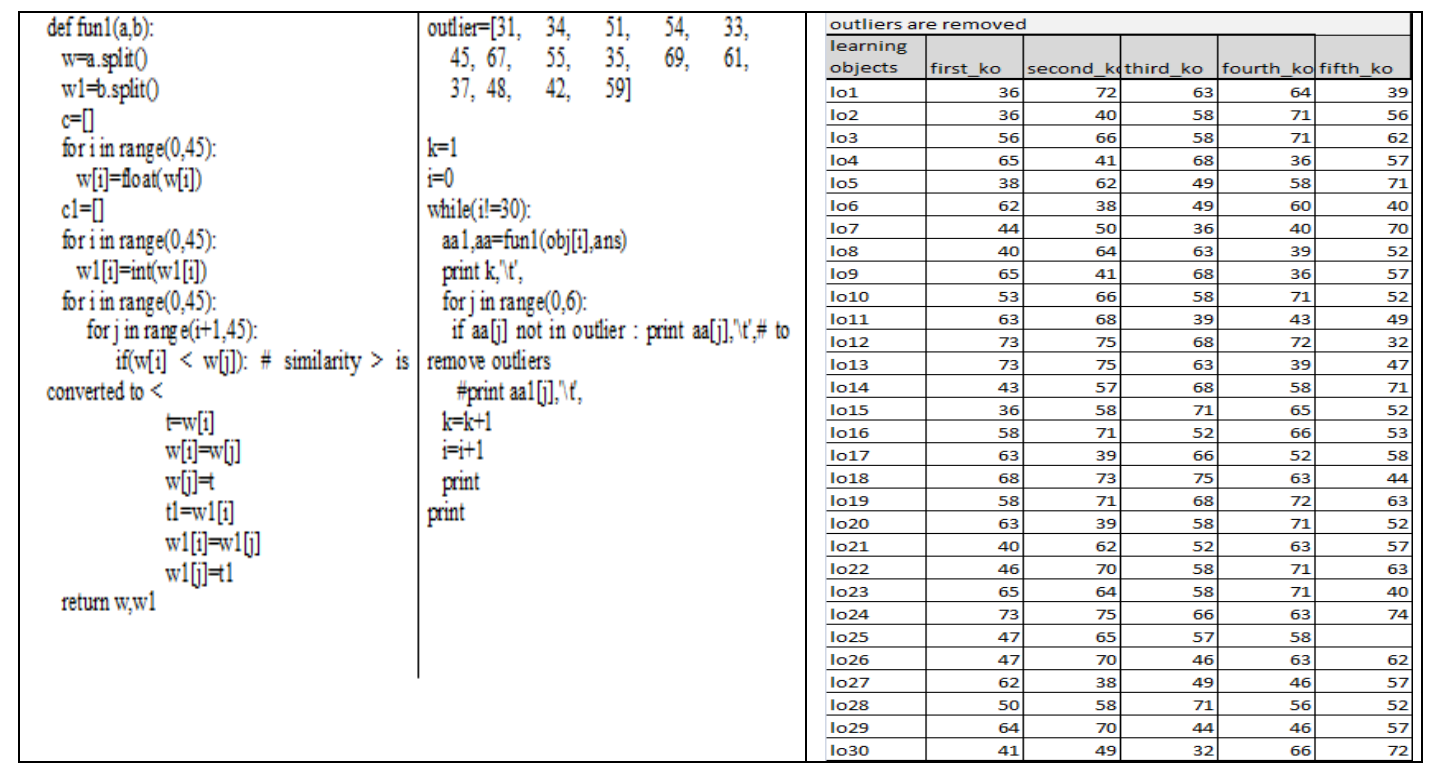

Figure 9. Function (Python) and Relevant KOs 
Step 5: According to the "Figure 9", LO1 nearest neighbours (Knowledge Objects) are: ID36, ID72, These ids can be considered and stored as extended metadata and it can be added as follows:

\begin{tabular}{|c|c|c|c|c|}
\hline id & $\begin{array}{l}\text { Metad } \\
\text { atal }\end{array}$ & $\begin{array}{l}\text { MLeta } \\
\text { data? }\end{array}$ & $\begin{array}{l}\text { MIeta } \\
\text { data } \\
\text { n }\end{array}$ & $\begin{array}{l}\text { KC as } \\
\text { Extend ed } \\
\text { Mietad ata }\end{array}$ \\
\hline $\begin{array}{l}\text { Lol } \\
\operatorname{Loz}\end{array}$ & - & - & 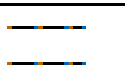 & $\begin{array}{l}\text { Ko36, } 10072 \\
K \circ 36,10040\end{array}$ \\
\hline $\mathbf{L} 03$ & - & - & - & - \\
\hline & - & - & & \\
\hline
\end{tabular}

Figure 10. Extended KOs

Step 6: The content of these ELOs can be delivered along with a clustered group of LOs or they can be summarised and delivered to the user. A clustering tool for k-mean clustering was used. The value of ' $k$ ' was taken as 6 . The clustered formed are shown below:

\begin{tabular}{|c|c|c|c|c|c|c|c|c|c|}
\hline SNO & topic & subtopic & LO_ID & KO_ID & KO_ID & KO_ID & KO_ID & KO_ID & CLUSTER_ID \\
\hline & \begin{tabular}{|l|l|} 
INTRODUCTION \\
\end{tabular} & DATA WAREHOUSE & 103 & 56 & 66 & 58 & 71 & 62 & C_kmeans_1 \\
\hline & DATA MINING TECHNIQUES & ASSOIATION & Io10 & 53 & 66 & 58 & 71 & & C_kmeans_1 \\
\hline 12 & 2 DATA MINING TECHNIQUES & CLASSIFICATION & Io12 & 73 & 75 & 68 & 72 & 32 & c_kmeans_1 \\
\hline & 6 OBJECTIVE MEASURE & SUPPORT & lo16 & 58 & 71 & 52 & 66 & 53 & C_kmeans_1 \\
\hline 18 & \begin{tabular}{l|l}
8 & OBJECTIVE MEASURE \\
\end{tabular} & LIFT & lo18 & 68 & 73 & 75 & 63 & 44 & c_kmeans_1 \\
\hline & 9 OBJECTIVE MEASURE & RECALL & Io19 & 58 & 71 & 68 & 72 & 63 & C_kmeans_1 \\
\hline 22 & 2 DATA MINING APPLICATIO & TEMPORAL MINING & 1022 & 46 & 70 & 58 & 71 & 63 & C_kmeans_1 \\
\hline 23 & 3 DATA MINING APPLICATIO & SPATIAL MINING & 1023 & 65 & 64 & 58 & 71 & 40 & c_kmeans_1 \\
\hline 24 & 4 DATA MINING APPLICATIO & TIME SERIES MINING & Io24 & 73 & 75 & 66 & 63 & 74 & c_kmeans_1 \\
\hline 26 & $\begin{array}{ll}6 \text { PRE PROCESSING } \\
\end{array}$ & DATA CLEANING & 1026 & 47 & 70 & 46 & 63 & 62 & C_kmeans_1 \\
\hline & 4 KNOWLEDGE DISCOVERY & PATTERN EVALUATION & 104 & 65 & 41 & 68 & 36 & 57 & C_kmeans_2 \\
\hline & \begin{tabular}{l|l}
9 & PATTERN EVALUATION \\
\end{tabular} & INTERESTING MEASURES & 109 & 65 & 41 & 68 & 36 & 57 & c_kmeans_2 \\
\hline 13 & 3 DATA MINING TECHNIQUES & PREDICTION & lo13 & 73 & 75 & 63 & 39 & 47 & C_kmeans_2 \\
\hline 17 & 7 OBJECTIVE MEASURE & CONFIDENCE & Io17 & 63 & 39 & 66 & 52 & 58 & C_kmeans_2 \\
\hline & $\begin{array}{ll}7 \text { PRE PROCESSING } \\
\end{array}$ & DATA SELECTION & 107 & 44 & 50 & 36 & 40 & 70 & C_kmeans_3 \\
\hline 11 & 1 DATA MINING TECHNIQUES & CLUSTERING & Io11 & 63 & 68 & 39 & 43 & 49 & c_kmeans_3 \\
\hline 27 & 7 PRE PROCESSING & DATA INTEGRATION & 1027 & 62 & 38 & 49 & 46 & 57 & c_kmeans_3 \\
\hline 29 & 9 PRE PROCESSING & DATA TRANSFORMATION & 1029 & 64 & 70 & 44 & 46 & 57 & C_kmeans_3 \\
\hline 30 & 0 PATTERN EVALUATION & INTERESTING MEASURES & 1030 & 41 & 49 & 32 & 66 & 72 & c_kmeans_3 \\
\hline & 2 INTRODUCTION & KNOWLEDGE DISCOVERY & 102 & 36 & 40 & 58 & 71 & 56 & c_kmeans_4 \\
\hline & 5 PRE PROCESSING & DATA CLEANING & 105 & 38 & 62 & 49 & 58 & 71 & c_kmeans_4 \\
\hline & 8 PRE PROCESSING & DATA TRANSFORMATION & 108 & 40 & 64 & 63 & 39 & 52 & c_kmeans_4 \\
\hline 14 & 4 DATA MINING TECHNIQUES & OUTLIER ANALYSIS & Io14 & 43 & 57 & 68 & 58 & 71 & c_kmeans_4 \\
\hline 15 & \begin{tabular}{|l} 
ISSUES \\
\end{tabular} & TASK PRIMITIVE & 1015 & 36 & 58 & 71 & 65 & 52 & c_kmeans_4 \\
\hline 21 & 1 DATA MINING APPLICATIO] & WEB MINING & 1021 & 40 & 62 & 52 & 63 & 57 & c_kmeans_4 \\
\hline 28 & 8 PRE PROCESSING & DATA REDUCTION & 1028 & 50 & 58 & 71 & 56 & 52 & C_kmeans_4 \\
\hline & 1 INTRODUCTION & DATA MINING & Io1 & 36 & 72 & 63 & 64 & 39 & c_kmeans_5 \\
\hline 25 & 5 DATA MINING APPLICATIO] & multimedia miming & 1025 & 47 & 65 & 57 & 58 & & c_kmeans_5 \\
\hline & 6 PRE PROCESSING & DATA INTEGRATION & 106 & 62 & 38 & 49 & 60 & 40 & c_kmeans_6 \\
\hline 20 & 0 DATA MINING APPLICATIO] & TEXT MINING & 1020 & 63 & 39 & 58 & 71 & 52 & c_kmeans_ 6 \\
\hline
\end{tabular}

Figure 11. Clusters 
Step 7: Learning Object_27 of cluster_3 belongs to the topic "data integration", the knowledge objects ko62, ko38, ko49 also belong to the same topic "data integration" as shown below. Thus for a given topic a set of LOs and relevant KOs can be delivered.

\begin{tabular}{|l|l|l|}
\hline PRE PROCESSING & DATA INTEGRATION & lo27 \\
\hline DATA INTEGRATION & SCHEMA INTEGRATION & ko62 \\
\hline DATA INTEGRATION & SCHEMA INTEGRATION & ko38 \\
\hline DATA INTEGRATION & SCHEMA INTEGRATION & ko49 \\
\hline
\end{tabular}

\section{Conclusion}

Instructional Theory is defined as identifying methods that will best provide the conditions under which learning goals will most likely be attained. The best instructional technique is determined by the objective(s) to be learned. One such objective for enhanced learning can be achieved by adding a $\mathrm{KO}$ as an extended metadata. Static learning content is enhanced by providing an expert knowledge (KO) as an added content to the learners. This content delivered is dynamic; knowledge enriched and can help learners specially the users of higher order thinking skills. This can help the student to get that extra edge of learning and prepare them for various forms of assessment. Embedding the $\mathrm{KO}$ with a LO gives a context-driven architecture in which the learner is provided with facts and information, thus multiple perspectives on the content are made available. Hence quality resources can be delivered to the student. These classified ELOs can be clustered or summarized and delivered.

\section{Abbreviations}

LO : Learning Object

KO : Knowledge Object

LMS : Learning Management System

KMS : Knowledge Management System

LOR : Learning Object Repository

KNN : K-Nearest Neighbour

MERLOT : Multimedia Educational Resources for Learning and Online Teaching

EDNA : The Education Network Australia

CAREO : Campus Alberta repository of educational objects

HEAL : Health education assets library.

LTSC : Learning Technology Standards Committee

\section{References}

[1] M. Ally, "Foundations of educational theory for online learning", In T. Anderson \& F. Elloumi (Eds.), Theory and practice of online learning. Athabasca, Canada: Creative Commons: Athabasca University, (2004).

[2] T. Barron, "Learning Object Pioneers", ASTD Learning Circuits. Retrieved 31 July, 2005, from: http://www.learningcircuits.org/2000/mar2000/barron.htm, (2000) November.

[3] Dublin Core Metadata Element Set, Version 1.1. DOI: 2012-06-14. Retrieved online 21-12-2011 from :http:// dublincore.org/ documents/de-ices/, (2012).

[4] Y. Eguigure, "Quality evaluation model for learning objects from a pedagogical perspective", A case study. Ibero American Journal of Applied Computing ISSN 2237-4523, (2011).

[5] J. Han and M. Kamber, "Data Mining: Concepts \&Techniques", Morgan Kaufmann Publishers ( $2^{\text {nd }}$ edition), An imprint of Elsevier, San Francisco, CA, ISBN:978-1-55860-901-3, (2008). 
[6] Horton. Designing Knowledge Objects. William Horton Consulting Inc. e-Learning by design, San Francisco, (2001).

[7] IEEE LTSC IEEE Standard for LO Metadata. 1484.12.1-2002. Available at http://Itsc.iee.org/wg12/, (2002).

[8] IMS, IMS Metadata Best Practice Guide for IEEE 1484.12.1-2002 Standard for Learning Object Metadata. Version 1.3. Retrieved online 21-12-2011 from http://www.imsglobal.org/Metadata/mdv1p3/ imsmd_bestv1p3.html, (2006).

[9] D. Merrill, "Knowledge Objects and Mental-Models The Instructional Use of Learning Objects", Available at http://id2.usu.edu/Papers/KOMM.PDF, (2006).

[10] D. Roy, S. Sarkar and S. A. Ghose, "Comparative Study of Learning Object Metadata, Learning Material Repositories, Metadata Annotation \& an Automatic Metadata Annotation Tool", Advances in Semantic Computing (Eds. Joshi, Boley \& Akerkar), vol. 2, (2010), pp. 103-126.

[11] J. Ruffner and N. Deibler, "Knowledge Objects and Learning Objects: Birds of a Feather or Different Species Altogether", The Inter service/Industry Training, Simulation \& Education Conference (I/ITSEC), (2008).

[12] S. A. Sabitha, D. Mehotra and A. Bansal, "Enhanced Learning through Learning Knowledge Object", IJETCAS, ISSN (Print): 2279-0047, ISSN (Online): 2279-0055, vol. 1, 2 \& 3, no. 4, (2013) March-May.

[13] SCORM, "Sharable Content Object Reference Model", Available at http://www.adlnet.org/scorm/index.cfm, (2005).

[14] V. Štuikys, "Towards knowledge-based generative Learning Objects. Information technology and control", vol. 36, no. 2. ISSN 1392-124X, (2007).

[15] P. N. Tan, M. Steinbach and V. Kumar, "Introduction to Data Mining", Pearson Education (6 $6^{\text {th }}$ Ed.), India. Chapter 9, ISBN: 978-81-317-1472-0, (2007), pp. 624.

[16] Wagner Steps to creating a Content Strategy for your organization. ELearning Developers Journal. ELearning Guild. Available at http://www.elearningguild.com/ pdf/2/102902MGT-H. Pdf, (2002).

[17] D. A. Wiley, "Connecting learning objects to instructional design theory: A definition, a metaphor, and a taxonomy", The Instructional Use of Learning Objects: Available at http:// reusability.org/read/chapters/wiley.doc, (2000).

[18] A. Zouaq1, N. Roger and C. Frasson, "Using a Competence Model: Aggregate Learning, Knowledge Objects”, at Seventh IEEE International, ALT, ICALT, 0-7695-2916-X/07, (2007).

\section{Authors}

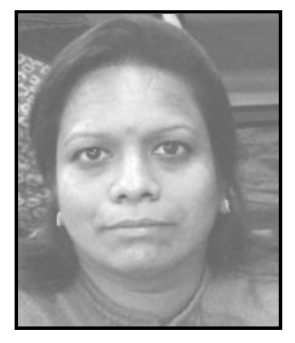

Mrs Sai Sabitha, is BE (CS), ME (CS) in Computer Science and engineering. She is Associate Professor (CSE), KEC Ghaziabad. She is pursuing Ph.D. Programming in Computer Science \& Engineering. She has published research papers in conferences \& journals. She has over 14 years of Academic and industry experiences. She has handled various B. Tech \& M. Tech Projects. Her area of interests are e-Learning, Knowledge Management, Data Mining, Artificial Intelligence \& Web Technologies.

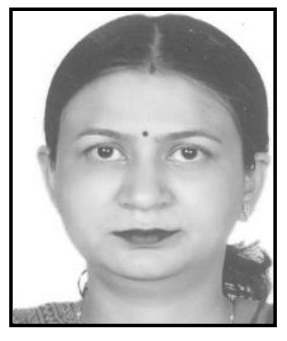

Dr. Deepti Mehrotra is a gold medalist of Lucknow University and had received Ph.D. from Lucknow University. Currently, she is Director of Amity School of Computer Science, Noida, India. She has more than 18 years of experience in teaching, research and content writing. She had published more than 50 papers in international refereed Journals and conference Proceedings. She is a member of many committees like member of Board of Study of various Universities, member of the DRC of Amity University and reviewer for many referred journals and conferences. She is regularly invited as resource person for FDPs and invited talk in national and international conference. She is currently guiding 7 Ph.D. and four M.Tech. scholars. 


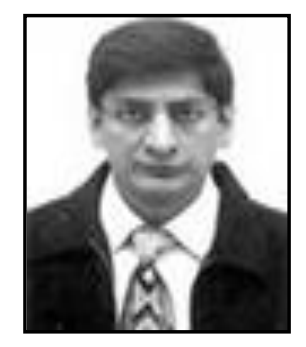

Dr. Abhay Bansal is BE (CS), ME (IT), MBA and PhD. He is Professor \& HOD (CSE), ASET \& Director, DICET, Amity University, Noida. With over 19 years of Industry and Academic Experience, Dr. Bansal has regularly contributed more than 40 papers in various International journals/conferences. He is a fellow of the Institution of Engineering and Technology (U.K), Sr. Member, International Association of Computer Science and Information Technology. He is a member of ISTE, IEEE (USA), ACM, IETE. He is also a Microsoft Certified Professional and Microsoft approved Technical Associate. He has been an active member and Chairman of the programme committees of several National and International conference/seminar. He is also a reviewer of various National/ International Journals of repute. 